Rhode Island College

Digital Commons @ RIC

$1-1-2014$

\title{
Educating Nursing Students on Emergency Preparedness: A Pilot Program
}

Sandra N. Burnock

Rhode Island College

Follow this and additional works at: https://digitalcommons.ric.edu/etd

Part of the Other Education Commons, and the Other Nursing Commons

\section{Recommended Citation}

Burnock, Sandra N., "Educating Nursing Students on Emergency Preparedness: A Pilot Program" (2014). Master's Theses, Dissertations, Graduate Research and Major Papers Overview. 231.

https://digitalcommons.ric.edu/etd/231

This Major Paper is brought to you for free and open access by the Master's Theses, Dissertations, Graduate Research and Major Papers at Digital Commons @ RIC. It has been accepted for inclusion in Master's Theses, Dissertations, Graduate Research and Major Papers Overview by an authorized administrator of Digital Commons @ RIC. For more information, please contact digitalcommons@ric.edu. 


\title{
EDUCATING NURSING STUDENTS ON \\ EMERGENCY PREPAREDNESS: \\ A PILOT PROGRAM
}

\author{
by \\ Sandra N. Burnock \\ A Major Paper Submitted in Partial Fulfillment \\ of the Requirements for the Degree of \\ Master of Science in Nursing \\ in \\ The School of Nursing \\ Rhode Island College
}

2014

\begin{abstract}
The purpose of this project was to determine if a disaster preparedness educational intervention for nursing students' could engage students in personal preparedness and enhance their willingness to respond during a public health emergency. The United States (U.S.) is among the top five countries in the world that experience frequent natural disasters (Guha-Sapir et al., 2012). With over 3.1 million nurses in the U.S. (AACN, 2011) and their importance to healthcare, the nursing profession plays a crucial role in the ability of the nation to prepare for and respond to disasters. Currently, however, nurses in the U.S. lack the knowledge, skills and
\end{abstract}


attitudes needed to effectively respond to disasters, thereby placing the public at risk. A pilot program was developed that introduced the topic of disaster preparedness to senior level nursing students through a one-hour course. The pilot program utilized a pre- and post-survey method to evaluate the effect of the education on nursing students. A convenience sample of 18 students participated in the class, course evaluation and pre-survey, and 14 students responded to the postsurvey request. Data were collected and analyzed on the course evaluation, measuring how well the course objectives were met and the appropriateness of the teaching strategies. Pre- and postsurvey results were compared to determine the effectiveness of the pilot program. The results indicated that the course encouraged nursing students to engage in preparedness, and to be willing to respond. No increased in pre-registration with a professional emergency preparedness organization was noted. Implications from this pilot program include the need for further studies regarding best methods for educating nursing students. Also, advance practice registered nurses need to lead the nursing profession in emergency preparedness to increase the resilience of the United States during disasters.

Table of Contents

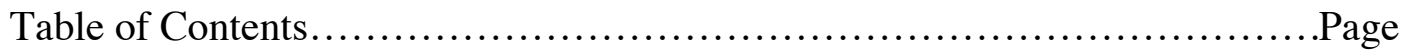

Statement of Problem.......................................................

Literature Review.....................................................6

Theoretical Frameworks................................................ 19

Methods................................................................. 22

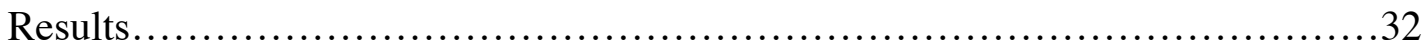

Summary and Conclusions................................................ 37

Implications for Advanced Nursing Practice................................43

References..........................................................47

Appendices.......................................................... 54 
Educating Nursing Students on Emergency Preparedness: A Pilot- Program

Statement of the Problem

The United States (U.S.) is among the top five countries in the world that experience frequent natural disasters (Guha-Sapir et al., 2012). With over 3.1 million nurses in the U.S. (AACN, 2011) and their importance to healthcare, the nursing profession plays a crucial role in the ability of the nation to prepare for and respond to disasters. Currently, however, nurses in the U.S. lack the knowledge, skills and attitudes needed to effectively respond to disasters, thereby placing the public at risk. To better prepare nurses, education and training should begin early in basic nursing programs, with continued learning about disaster preparedness following graduation. This continuing education would facilitate nurses' readiness to effectively participate during times of extreme emergencies.

Based on the significance of this problem, a pilot educational program was developed, implemented and evaluated to inform the education of nursing students about emergency preparedness and response and to gauge their willingness to volunteer in a disaster before and after the educational intervention.

\section{Background and Significance}

At any given moment a disaster can strike, creating a serious public health emergency. Disasters resulting from adverse weather are easily predicted through monitoring, thereby giving an opportunity to prepare for the immediate threat. Other disasters, such as terrorist attacks and infectious disease outbreaks, are less predictable. Despite the differences in predictability, all disasters call for a planned public health response that protects the general population from the disaster itself, as well as the subsequent effects. The American Public Health Association (APHA) defines disasters as any event, either natural or man-made, that can cause destruction on three levels including loss of human life, physical damage and environmental damage. The APHA further states that disasters can interfere with health services and the resilience of an affected community and, therefore, require a response from outside the disaster zone (APHA 2006). 
Unfortunately, the prevalence of disasters is alarmingly high; with an estimated 450 - 800 events reported each year (World Health Organization [WHO], 2007b). In addition, the incidence rate of reported world disasters increased by $60 \%$ between the years of 1997 - 2006, as compared to the previous decade (World Health Organization [WHO], 2007). The Center for Research on the Epidemiology of Disaster reported 357 natural disasters throughout the world in 2012, killing 9,652 people and affecting 124.5 million (Guha-Sapir, Hoyois, \& Below, 2012).

Historically, the U.S. has experienced natural disasters such as wild fires, flu epidemics, hurricanes and tornadoes that not only claim the lives of thousands, but also create situations that require a rapid public health response to limit negative health and economic consequences. This situation was seen with Hurricane Katrina in 2005, which resulted in 1200 reported deaths (National Hurricane Center, 2012). Another example of the need for a rapid response was Hurricane Sandy in 2012, responsible for killing 131 people and leaving an estimated eight million people without power (National Weather Service, 2012). This hurricane was noted to be the most costly natural disaster throughout the world in 2012 (Guha-Sapir et al., 2012).

In addition to natural disasters, man-made disasters such as terrorist attacks pose a threat to the United States, as was apparent after the September 11, 2001 World Trade Center attack and subsequent intentional anthrax exposures. These events marked a turning point in emergency preparedness, as the nation was forced to address the gaps and vulnerabilities within the nation's preparedness plans related to terrorist attacks. Evaluation of the nation's vulnerabilities led to the conclusion that emergency preparedness was crucial at every level, from individual, to community health departments, extending up to federal agencies (Khan, 2011).

Part of the response to this evaluation was passage of the Pandemic and All Hazards Preparedness Act (PAHPA) in December of 2006. This law (no. 109-417) required public health preparedness plans to include medical preparation and response to all hazards that may be encountered (U.S. Department of Health and Human Services [USDHHS], 2013). In addition, The Federal Emergency Management Agency (FEMA) released a "national preparedness goal" in 
2011, which incorporated the idea of community resilience, or a community's ability to identify, respond to, and recover from any potential or actual disaster. This concept of resilience was also reflected in the Healthy People 2020 goals related to disaster preparedness, which included community resilience as a national goal (U.S. Department Of Health and Human Services [USDHHS], 2012). All of the above actions indicated the need for preparedness at all levels of the nation.

Healthcare workers are well positioned to lead the nation in emergency preparedness and response, given ongoing education and training in the management of natural and manmade disasters and terrorist attacks. Especially for biological threats, healthcare workers are in a critical position to protect the public by identifying initial symptoms of exposure or by quickly recognizing epidemiological patterns (Steed, Howe, Pruitt, \& Sherrill, 2003; Weiner, Irwin, Trangenstein, \& Gordon, 2005).

Nurses represent the largest group of healthcare workers (American Association of Colleges of Nursing [AACN], 2011), and are recognized as playing key roles in emergency preparedness and response; as reflected in higher staffing demands during significant disasters (Pang, Chan, \& Cheng, 2009; Lavin, 2006). Nurses practice in a variety of settings, from acute care hospitals to long-term care facilities and community clinics. Regardless of their practice setting, all nurses need to be educated in potential disasters and emergency response (Veenema, 2006). The National Student Nurses Association (NSNA) recognized this need when it created the Disaster Project to emphasize the importance of equipping undergraduate students with the knowledge and training needed to respond effectively during disasters (NSNA, 2013).

In a concept analysis, Slepski (2005) proposed the following definition of emergency preparedness as it specifically relates to nursing;

"Emergency preparedness is the comprehensive knowledge, skills, abilities, and actions needed to prepare for and respond to threatened, actual, or suspected chemical, biological, radiological, nuclear or explosive incidents, man-made incidents, natural disasters, or other related events (p. 426)."

This definition can serve as a guide for nurses in their development of exemplary emergency 
preparedness. This high level of preparation includes having knowledge of the potential threats, possessing proper assessment skills to make a diagnosis, ability to respond to a threat in a quick and efficient manner; and to take proper preemptive actions, such as personal preparedness, to be available during an emergency.

So what is the best way to develop nurses' knowledge, skills and attitudes related to emergency preparedness and response? One of the themes reflected in the literature suggests that schools of nursing need to incorporate relevant topics into their curricula. Since the September $11^{\text {th }}$ attacks, nursing emergency preparedness and response has improved, as evidenced by multiple protocols, competencies and guidelines being established by national nursing organizations. In 2001, the International Nursing Coalition for Mass Casualty Education (INCMCE) was formed with representatives from schools of nursing, nursing accrediting bodies, nursing specialties and government agencies. The goal of the INCMCE was to increase mass casualty education throughout nursing schools (Weiner et al., 2005). The NSNA released a resolution entitled; The Establishment of Protocols for Disaster Relief Guiding the Scope of Practice for Student Nurses and the Collection and Distribution of Donations. This resolution, as described in Appendix I of the NSNA's Guidelines for Planning Disaster Preparedness, Recovery and Relief, listed guidelines for nursing student involvement during a disaster, and developed a goal to increase the number of students educated to participate in emergency response activities (NSNA, 2013). Similar efforts were seen by the American Association of Colleges of Nursing (AACN) in 2008, when they incorporated emergency preparedness and disaster response into the Essentials for baccalaureate curricula, with the expectation that bachelors-prepared nurses would have a general understanding of environmental factors that contribute to disasters, and the risks that nurses and patients face as a result of these factors. The Association of State and Territorial Directors of Nursing (2008) created 12 core competencies that addressed roles and expectations of public health nurses in an emergency response and the Association of Community Health Nursing Educators (ACHNE) created a task force in 2007 to 
develop guidelines for proper emergency preparedness education, curricula, and resources (Kuntz, Frable, Qureshi, \& Strong, 2000). With the increasing recognition of disaster preparedness and response as a core competency within the nursing profession, these national organizations have developed consistent standards to guide the integration of this topic into nursing curricula.

\section{Literature Review}

A review of pertinent literature was done to explore the topic of disaster preparedness and response and the benefits of incorporating related content into nursing school curricula. The online database CINHAL Plus was used and keywords included: disaster preparedness, emergency preparedness, nursing students, and nurses. Both research studies and professional articles were included in the search that involved the topics of disaster preparedness, experiences of nurses during disaster responses, barriers to nurses' willingness to respond during an emergency, methods of incorporating disaster preparedness content into curricula for nursing students, and challenges to introducing new content into nursing curricula. The literature was organized into six categories: application of the nursing process to disaster preparedness; learning from past events; nurses’ perceptions, willingness and barriers to emergency preparedness; ethical issues; implementing disaster preparedness curricula in schools of nursing; and methods of teaching undergraduate nursing students about disaster preparedness.

\section{Application of the Nursing Process to Disaster Preparedness}

Nurses' diverse specialty areas and practice settings enhance their potential to positively impact a large portion of the population during a disaster. A position paper released by the 
Association of State and Territorial Directors of Nursing (ASTDN, 2008) identified public health nurses as key stakeholders in emergency preparedness, given their ability to both act as first responders during an event, while also maintaining a broad population focus. Public health nurses have the skills and knowledge to perform essential tasks such as developing, implementing and evaluating emergency preparedness policies and training exercises. These skills have been developed through extensive preparation and experience in using the nursing process. The nursing process, which includes assessment, planning, implementation and evaluation, is the foundation that guides all nursing practice. The ASTDN position paper promotes use of the nursing process during all phases of disasters, including: mitigation, preparedness, response and recovery (Jakeway, Larosa, Cary, \& Schoenfisch, 2008). Mitigation refers to preventing and minimizing disaster effects, preparedness indicates the ability to respond effectively to a disaster event, the response phase includes having the knowledge to safely respond to an event and provide community support and, finally, the recovery phase requires the ability to return an affected community back to a functioning state (Jakeway et al., 2008). The position paper provides examples of ways that public health nurses can combine each aspect of the nursing process with each phase of disasters, indicating how public health nurses are beneficial planners and responders in all phases of disasters.

Another article titled "Nursing Process and Critical Thinking Linked to Disaster Preparedness" echoes this idea of using the nursing process in disaster preparedness. The authors formulate three main hypotheses. The first is that "the nursing process with its deliberate, cyclical and evaluation steps, is a particularly helpful model in a disaster response at the individual and institutional levels" (Bulson \& Bulson, 2011, p. 478). Rather than defining the roles of public health nurses, however, the author's focus on how acute care nurses in hospitals can use the nursing process in the event of a disaster. The second hypothesis discusses how nurses develop critical thinking skills, which in combination with the nursing process enhance the ability to prepare for and respond to disasters. The final hypothesis is that just as the nursing process and 
critical thinking skills are taught during nursing school, the concept of disaster preparedness should also be introduced to nursing students. Bulson and Bulson (2011) explain how they integrated the nursing process, critical thinking and disaster preparedness into three different nursing programs, emphasizing nurses' need to be knowledgeable of individual and community disaster preparedness. These articles highlight a common theme throughout the literature that nursing as a profession, regardless of specialty area, can influence and impact disaster preparedness and response through use of the nursing process.

\section{Learning From Past Events}

As evidenced by the aforementioned data, disasters are a common occurrence throughout the world. The following papers highlight important lessons learned from past events and explain how to improve national emergency preparedness through education and training in nursing schools. Veenema (2006) refers to the emergency response efforts seen after the 2001 terrorist attacks, citing that nurses wanted to actively participate, yet did not know how to communicate with emergency response organizations, and lacked the skills needed to respond both safely and effectively to the disaster. These gaps in knowledge prompted schools of nursing to take action to develop multiple graduate, post-graduate and certificate programs in emergency management.

A major problem frequently encountered during disasters is the arrival of volunteers, both professional and non-professional, who lack proper training and credentials. These untrained professionals deplete scarce resources, as they require emergency management personnel time for training and supervision, when these personnel could be better used for other disaster response activities. The recommendation to prevent this problem is to have professionals pre-register with a response organization such as the Medical Reserve Corps (MRC), Emergency System for Advance Registration of Volunteer Health Professionals (ESAR-VHP), or the Disaster Medical Assistance Team (DMAT) (Peterson, 2006; Merchant, Leigh, \& Lurie, 2010). Professionals who pre-register have the opportunity to participate in drills and exercises that prepare them to provide efficient and effective care to the public during an extreme emergency.

When nurses volunteer with an organization and/or respond to their place of employment 
during an emergency, challenges arise. In 2005, a descriptive study after Hurricanes Katrina and Rita assessed the challenges faced by healthcare workers (Rogers and Langdon, 2007). Seven hundred and twenty-five health care workers responded to a survey about their experiences, including 214 nurses. Thirty-three percent of the respondents stated that communication was the greatest obstacle during the hurricane response, while $22 \%$ cited "red tape with volunteering" as the biggest hindrance. The study cited that respondents described confusion between different organizations, not knowing who to report to, or where to get supplies. One respondent stated she was sent by the State of Maryland to respond, but due to lack of networking with proper organizations at the site of the disaster, her team of one hundred nurses became more of a burden than anything else (Rogers \& Lawhorn, 2007). This echoes the need stated above for nurses to plan and organize their disaster response effort prior to an actual event.

\section{Nurses' Perceptions, Willingness and Barriers to Emergency Preparedness}

There is an identified gap in the literature about nurses' and nursing students' perceptions of disasters, perceived professional roles and responsibilities, and educational needs (Baack \& Alfred, 2013; Olivia, Claudia, \& Yuen, 2009). Understanding nurses' perceptions and educational needs related to disaster preparedness could guide curricular content and potentially breakdown common barriers to active nursing involvement. A study surveying 164 Hong Kong nurses about their perception of disasters (Olivia et al., 2009) revealed that $21 \%$ of nurses who responded chose to characterize disasters as "unpredictable, sudden, unexpected and unpreventable," while $8.1 \%$ of respondents chose "out of control, cannot manage and do not know how to manage." Other descriptive terms used were "urgent quick," "horrible happening/traumatic/crisis/danger" and "unknown disease with no treatment available for the time being." The majority of nurses $(61 \%)$ also considered disasters to be events with the most number of victims rather than events with the most number of deaths. The population of nurses 
surveyed lived in a relatively disaster-free area. The focus on disaster preparedness, however, became more prominent following the nearby 8.0 earthquake in Sichuan, China in May of 2008.

The implications of this study are two-fold. First, no area is necessarily spared from potential disasters, and at any given moment, a natural or man-made disaster can strike any location; so nurses in all geographic locations need to be trained in disaster preparedness. Second, the descriptive terms chosen by the nurses also revealed a need for training, so that they could effectively and safely respond to a disaster, as opposed to feeling unprepared and out of control. The study prompts a conclusion seen throughout the literature, that nurses are not well educated in disaster topics and that nursing schools should include disaster-related content in their curricula. The authors further recommend that a disaster-nursing specialty be developed as a postgraduate program (Olivia et al., 2009).

A study surveying rural nurses in Texas found similar results regarding nurses' perceptions about disaster preparedness. The study surveyed 620 nurses working in various specialties throughout Texas. Utilizing an EPIQ summed score, with a median of 82.5 and a mean of 90 , the results verified that nurses perceived a low level of competence with regard to disaster preparedness, and further stated that they did not feel prepared to respond to a largescale disaster. The nurses who did report a higher level of confidence were more likely to have been involved in a disaster relief effort in the past (Baack \& Alfred, 2013). Other conclusions from this study were that nurses need to be actively involved in volunteer organizations such as the MRC, to gain experience and to feel more confident, and for all nurses to receive training in disaster preparedness.

Based on the literature review, one can conclude that all nurses must be prepared for disasters, no matter what their geographical location or area of nursing practice. Through increasing awareness of potential disasters, and by clarifying nursing roles and responsibilities before and after a disaster, nurses will be better equipped to face the myriad of challenges associated with disaster response. Furthermore, the above studies indicate that nurses who have past exposure to disaster preparedness, or are involved with an organization that provides 
training, report a higher confidence level in responding to a disaster.

\section{Ethical Issues}

In addition to a lack of disaster education and training, nurses often face ethical concerns that translate into barriers to volunteering. The American Nurses Association (2010) stated that nurses may not respond to a disaster because of fears about personal safety in a disaster setting, concern for their family's welfare, ethical issues such as not having enough supplies to care for everyone, and legal issues such as protecting their license (Brewer, 2010). This construct of disaster ethics is widespread throughout both the nation and the world.

As a means to educating nurses and other healthcare workers on this topic, the Wisconsin Division of Public Health, Hospital Emergency Preparedness Program and the Wisconsin Hospital Association developed informational brochures regarding the ethics of disaster preparedness. The goal of these brochures was to generate an awareness of potential ethical issues that could arise during disasters, as well as to provide clarification about expectations during extreme emergencies. Realities of disasters, such as some people will die and others may not receive treatment, are discussed as ethical issues commonly associated with the response phase. Having a general awareness of this harsh reality before a disaster strikes prepares healthcare workers for what they may confront during an actual event (Wisconsin Flu Resource, n.d.).

Two studies evaluating the response efforts during the 2003 Severe Acute Respiratory Syndrome (SARS) outbreak demonstrate the ethical concerns, perceptions and experiences of nurses during a time of disaster. One study from Canada surveyed 941 community nurses during the SARS outbreak. Sixty-six percent of nurses stated that they experienced increased hours, more paperwork, and short staffing; which contributed to increased anxiety levels. Thirty percent of nurses reported fears associated with working with a contagious disease and becoming infected, or infecting family members. Nurses reported feeling shunned by others who were afraid they would pass on the disease, given their work with contagious people. In addition, the study noted fears of patients about contracting the disease from nurses (Bergeron, Cameron, 
Armstrong-Strassen, \& Pare, 2006).

A similar study evaluating the SARS response in Hong Kong surveyed 753 female nurses. Twelve percent of the nurses felt that they should not have to take care of SARS patients, $25.9 \%$ considered leaving their jobs due to the threat of contracting the disease, and $7.6 \%$ agreed with both of the above statements. In addition, approximately $50 \%$ of the nurses stated that there was an increased workload and $32.4 \%$ reported being avoided by the general public because of their profession (Shiao, Koh, Lo, Lim, \& Guo, 2007). Although no one can prevent the increased workload and probable stress associated with disaster responses, these studies indicate the need for nursing education that addresses the fears associated with working during a disaster.

Discussion of the ethical issues and professional obligations prior to a disaster supports the best possible outcomes, such as increased numbers of nursing volunteers who know how to effectively respond to the event.

In contrast to the previous studies that indicated a hesitation for nurses to respond, one study reported positive replies from nursing students at a University in Canada. Researchers distributed 1,512 surveys to students and had 484 responses. Reported results were that $67.9 \%$ of nursing students were willing to volunteer during an influenza outbreak and $77.4 \%$ were willing to volunteer if protective equipment was provided. In addition, the vast majority of the students (70.7\%) considered volunteering as a professional obligation (Yonge, Rosychuk, Bailey, Lake, \& Marrie, 2010). This study once again supported the need to integrate emergency preparedness content into nursing curricula, to reduce fears associated with disasters, and to increase nurses' willingness and ability to respond effectively.

\section{Implementing Disaster Preparedness Curricula in Schools of Nursing}

The evidence clearly indicates that nurses are essential to disaster preparedness and response due to their skills and knowledge grounded in the nursing process. Despite this fact, it is also clear that nurses possess different levels of knowledge and confidence in disaster preparedness, which demonstrates the need for ongoing education in this area. Multiple sources suggest that nurses need to learn about disaster preparedness, and the best place to begin this 
educational process is in nursing schools (Bulson \& Bulson, 2011; Buyum, Dubruiel, Torghele, Alperin, \& Miner, 2009; Culley, 2010; Hutchinson et al., 2011; Kuntz et al., 2008; Steed et al., 2003).

A pertinent area explored in the literature was the content related to emergency preparedness and response in nursing curricula and the challenges to integrating this content. Three studies explored the current content about disaster preparedness in nursing school curricula. One of the studies specifically identified a gap in current research about approved curricula. All three of the studies acknowledged the major challenge of adding new content to nursing school curricula, due to the amount of content already required for accreditation (Buyum et al., 2009; Schmidt et al., 2011; Weiner, E., Irwin, M., Trangenstein, P., \& Gordon, J. 2005).

Subsequent research examined the effects of two emergency preparedness summits on faculty perceptions of their curricula (Buyum et al., 2009). The summits invited faculty from all nursing programs in Georgia to attend educational sessions and to brainstorm ideas about how to incorporate emergency preparedness into current nursing curricula. Following the summit, a survey was sent to participants to evaluate the effectiveness of the training. A mean score of 4.4 (on a 5.0 Likert Scale) demonstrated that most faculty found the information presented useful. In particular, the survey results revealed that the summits helped faculties to identify gaps in their current content; including topics like explosive agents, mass casualty training, bioterrorism response, and triage training. In addition, faculty cited communication with other emergency preparedness personnel as one of the biggest barriers, reaffirming the need for healthcare professionals to practice communications through interdisciplinary drills. Another finding of the study was that $40 \%$ of participants reported actively attempting to change curricula to include more emergency preparedness topics. The research concluded that nurses were currently unprepared to participate in emergency preparedness activities, and the best way to improve the situation is to incorporate pertinent content into the nursing curriculum (Buyum et al., 2009).

Another study surveyed deans and directors of nursing programs throughout the United States to assess the extent to which emergency preparedness was included in their curricula 
(Weiner et al., 2005). A total of 348 schools responded to the survey. Approximately $32 \%$ stated that the school included disaster preparedness during the years of 2000 and 2001, with an increase to $53 \%$ during the years of 2002 and 2003. This increase was likely in response to the terrorist attacks in 2001, which motivated preparedness initiatives throughout the nation. This trend was also noted with respect to content of curricula, with the majority of the content from 2000 to 2001 being centered on natural disasters, but then changing to a focus on biological agents from 2002 to 2003 . The survey revealed that $74 \%$ of the nursing deans/directors did not think that their faculty had the expertise to teach content on disaster preparedness (Weiner et al., 2005). Overall, this study confirmed that disaster preparedness was lacking in nursing school curricula. In addition, the study identified limited faculty expertise in emergency preparedness and response as a barrier.

Finally, Schmidt et al. (2011) conducted a study to evaluate how well prepared nursing students were for a disaster. A total of 1,351 nursing students responded to the survey. An overwhelming majority (95.6\%) agreed that disaster preparedness should be included in nursing curricula, however, only $64.7 \%$ responded that they talked about disasters within their school. This substantiates the theme in the current literature that nursing students are not adequately educated about disaster preparedness and response.

\section{Methods of Teaching Undergraduate Nursing Students about Disaster Preparedness}

Given the established need to integrate knowledge, skills and attitudes related to disasters into nursing curricula, the next areas examined were the necessary content and best teaching strategies to use for this education. One of the essential elements identified in the literature was the key concept of personal preparedness. All volunteers, including nurses, need to be confident about their own and their families' safety. A lack of assurance of this level of security can result in a decreased willingness to respond and an inability to focus during a disaster (Adams \& Canclini, 2008; Baack \& Alfred, 2013; Schmidt et al., 2011; Veenema, 2006). Furthermore, one study noted that following a disaster engagement exercise with nursing students; the students reported that their personal preparedness increased (Adams \& Canclini, 
2008). This finding indicates how education prior to an event can enhance self-confidence in preparedness. Schmidt et al. (2011) surveyed nursing students regarding disaster preparedness and their perceptions about personal preparedness. Over half of the students $(56.1 \%)$ reported not having a personal disaster plan, only $49.9 \%$ stated that they knew how much food and water they needed to store if they had to shelter at home, and approximately $50.6 \%$ stated that they had the supplies needed to shelter at home. These numbers support the need for education to encourage personal preparedness, as only $64.7 \%$ of the students had indicated that they talked about disaster preparedness in school.

There is some evidence in the literature that supports the use of certain methods in teaching about disaster preparedness. Two studies used simulation as the teaching method. In the first of these studies, Hutchinson et al., (2011) used a lecture regarding disaster preparedness and a simulation of a chemistry lab explosion. Eighty-one undergraduate students' test scores were analyzed revealing a higher level of knowledge following the disaster simulation exercise. The study concluded that a lecture followed by a simulation experience was an effective way to improve the knowledge base of undergraduate students.

Comparable results were noted in another investigation that evaluated 10 hours of lecture followed by a disaster simulation (Kaplan, Connor, Ferranti, Holmes, \& Spencer, 2011). This study utilized a 5-point Likert scale to evaluate the effectiveness of the program. This teaching approach proved to be effective, as evidenced by a mean score of 4.51 on 'increased knowledge base' and a mean score of 4.41 on 'more confidence in ability to handle emergencies' (Kaplan, et al., 2011). Both studies supported the efficacy of following a didactic session (lecture) with an application exercise (simulation).

A similar, yet more intensive, pilot program was developed for undergraduate students in China. Students were required to attend a 2-week, three credit course with a total of 60 contact hours. The course used the International Council of Nursing (ICN) disaster nursing competencies as the framework for the program. The course consisted of only five hours of lecture with the 
majority of the time focused on small group problem solving. In addition, practical hours in the simulation lab were utilized. The analysis of data from the pre- and post-test for this program demonstrated that the students felt that the course prepared them with the knowledge needed to respond to a disaster, but indicated a need for more application opportunities (Pang et al., 2009).

A final investigation involved a creative way to incorporate disaster preparedness into a nursing school curriculum. This study evaluated how one university created their own Medical Reserve Corps (MRC) as a means to provide education, training, drills and protection for the community. Nursing students' participation was mandatory. The university MRC participated in events such as promoting healthy lifestyles, mass prophylaxis/vaccinations drills, training as first responders, online Incident Command System (ICS) training and other educational opportunities for faculty and students. A 2006 survey regarding participation in the program revealed that $81 \%$ of those involved stated that they would be willing to volunteer in an actual emergency (Culley, 2010). This study focused on major components of emergency preparedness that were reflected in the literature - the need for nursing student education, as well as the importance of preregistration with an emergency response agency.

Based on the research evidence, it is clear that nurses have the potential to play a pivotal role in national emergency preparedness and response efforts. Their ability to apply the nursing process to assessment, planning, implementing and evaluating disaster-related activities could be invaluable to our country. Despite their professional competence, however, many nurses lack an understanding of what disaster preparedness entails, and what their roles and responsibilities are in times of extreme emergencies. Integrating emergency preparedness and response into nursing curricula is essential to equipping the nursing workforce for their critical role in local and national disasters.

The next section will discuss the theoretical frameworks and models used to guide the development of this program plan. 
Theoretical Frameworks

\section{Ecological Theory}


Two theoretical frameworks guided the development of essential content and effective teaching strategies for this pilot educational program. First, ecological theory was used to explain factors that influenced the student learner. Ecological theory, as proposed by Bronfenbrenner (1977), states that human development is the result of interrelated systems that are independent while still influencing each other. Specifically, the environment must be taken into account as an influencing factor. This ecological approach has informed the development of other models. For example, the Center for Disease Control and Prevention (CDC) applied the ecological theory to create a social-ecological model of violence prevention. In this model four systems were evaluated for violence prevention: society, community, relationships and individuals (Dahlberg \& Krug, 2002). In another example, Beaton et al. (2008) developed a model of disaster management based on the ecological theory. This model illustrated how factors at the individual, workplace, community, and state levels all needed to be evaluated for disaster preparedness and, additionally, how a deficiency in the management at one level could affect overall preparedness. For example, if individuals have no personal preparedness plan when a disaster strikes, that could negatively impact whether the community is able to respond as a whole.

The ecological model of disaster was applied to this pilot educational program, as reflected in learning outcomes related to the different levels of disaster preparedness, their interconnectedness and interdependence. Teaching at the individual and family level emphasized personal preparedness plans that enabled the student nurses to be available during emergencies. The workplace level content focused on the importance of knowing employer emergency plans. Finally, on a state and national level, instruction stressed the need to participate in response teams such as the MRC, and to understand how federal organizations communicate with each other. The educational intervention emphasized that each level of preparedness was important to the overall plan, and that one ill-prepared level could drastically impact the ability of the entire system to effectively respond to a disaster, exemplifying the interconnectedness of the model.

\section{Constructivist Learning Theory}

The second framework applied to this pilot educational program was the constructivist 
learning theory, based on Piaget's work. This theory guided the development of course content and teaching methods, in that students were encouraged to use their experiences and previous knowledge to help construct new knowledge (Hoover, 1996; McEwen \& Wills, 2011). Constructivist theory implies that learning should be active to facilitate the development of critical thinking skills (Brandon \& All, 2010; (Chikotas, 2008). In addition, constructivism assumes that learning is related to the sociocultural factors of the individual (Peters, 2000); mirroring aspects of the ecological model.

A constructivist concept applied during this educational program was problem-based learning. This method uses case studies and student's previous knowledge to discuss and form solutions to real life problems. The role of the teacher during problem-based learning is to help guide the discussion of key concepts, instead of just reciting facts for the students to learn. Students uncover knowledge through discussion with others (Brandon \& All, 2010; Chikotas, 2008; Peters, 2000). Case studies and discussion were used in this pilot program to help students explore personal preparedness, community collaboration and ethical dilemmas faced during a disaster. Students were also encouraged to use prior knowledge and experience with disasters to guide their problem solving of the case studies.

\section{National League for Nursing Excellence in Nursing Education Model}

The educational model from the National League for Nursing (NLN) that was developed by Brandon \& All (2010) was used to design the disaster preparedness educational intervention. The NLN model promotes an active learning environment that supports constructivism theory. This model identifies essential characteristics of nursing students needed to provide high quality care. Characteristics include the following: (a) being aware of how to utilize and network with various resources throughout the community, (b) maintaining confidence during ambiguous situations, (c) acting as a leader, (d) thinking critically and finally (e) functioning in the midst of a conflict. The model further suggests components of a curriculum that supports development of 
the above characteristics. Included in these components are having well prepared faculty, qualified students, an evidence based program, interactive teaching style and expertise in the content area (National League for Nursing, 2006). This model was used as a guide for developing educational program content, expected learning outcomes and style of teaching.

The next section will discuss the methods used during the development of this program plan.

\section{Methods}

The purpose of this project was to determine if a disaster preparedness educational intervention would engage nursing students in personal preparedness and enhance their willingness to respond during a public health emergency.

\section{Design}

This pilot program utilized a pre- and post-survey to describe the effects of the educational intervention (see Appendix A). A pre-survey was administered to each participant prior to the start of the educational intervention and asked the student nurse:

"Do you currently have a personal preparedness disaster plan?" 
"Are you willing to respond as a student nurse or as a graduate nurse during a public health disaster?"

"Are you presently pre-registered with a volunteer disaster response organization such as the Medical Reserve Corps or the American Red Cross?"

Following the pre-survey, a one-hour didactic and case study intervention was delivered to the nursing students. Students were asked to voluntarily provide an e-mail address, and after the intervention, students were asked to complete the class evaluation using a 5-point Likert scale (see Appendix B). Three weeks following the education, the post-survey was administered to those students who provided e-mail addresses, asking them the same three questions that were on the pre-survey. The fourth week after the class, a reminder e-mail message was sent to all who provided e-mail addresses to encourage completion of the post-survey.

\section{Sample/Participants}

The target population for this educational program was nursing students, who were identified using nonprobability, purposive sampling. This convenience sample of participants consisted of senior-level nursing students enrolled in one section of the Public and Community Health Nursing course. For this pilot program, the goal was to have 15 students participate in the educational intervention and to complete both pre- and post-surveys. Enrollment in the course and attendance during the educational intervention were the only inclusion criteria.

No demographic information was requested of students to maintain anonymity, however general information was collected from the professor following the class. Enrollment for the class consisted of 19 students, 14 female and 5 male. Eighteen of the students were basic Bachelor of Science in Nursing (BSN) students and one student was earning a second BS degree. All students worked part time in a variety of settings, including acute care, home care, long-term care or mental health facilities.

Site 
The pre-survey and educational intervention took place at Rhode Island College (RIC) after the RIC Institutional Review Board (IRB) conferred exempt status. The implementation occurred in the students' designated course classroom and, therefore, no cost was incurred. The classroom was an appropriate setting to promote learning, as teaching technology was available to support the educational intervention.

\section{Needs Assessment}

Assessment of the need for undergraduate nursing education in emergency preparedness was based on the student investigator's clinical experience at the Rhode Island Department of Health's (RIDOH) Center for Emergency Preparedness and Response (CEPR). Emergency management experts in the CEPR oversee the Strategic National Stockpile (SNS), a grant funded program that provides mass dispensing of medical countermeasures to the general public. The CEPR works with directors of municipal Emergency Management Agencies (EMA) to engage doctors, nurses and pharmacists in emergency response efforts. Each municipality is required to include medical professionals, such as prescribing practitioners and pharmacists in their emergency plan; but only a small portion of municipalities fulfilled this requirement. In addition, nurses were rarely included in emergency plans despite their recognized value during disasters. Given this information, the investigator searched the literature related to nursing education in emergency preparedness and response. The literature, as discussed earlier, suggested that nursing education in emergency preparedness should start in undergraduate school as a means to help engage more professionals. This clinical experience and literature review were the basis for the development of the pilot educational program.

\section{Intervention}

The content included in this educational program was derived from the literature review and developed using the selected theories and model. Content began with the topic of personal preparedness, including what nursing students needed to do to prepare both personally and 
professionally. Barriers to disaster response were discussed through case studies that addressed professional, ethical and legal considerations. The lack of communication during an emergency was noted in the literature as a major barrier to effective response, so the importance of registering with a recognized medical volunteer group was also discussed, along with the registration procedure.

The next content area provided background on potential threats and the need for an "allhazards approach." This concept emphasized the importance of being up-to-date on likely geographical threats as well as other potential disasters.

Finally, educational opportunities were presented and students were encouraged to register with organizations such as the MRC, which sponsors drills and exercises throughout the year for nurses and students. Lectures and case studies were supplemented with handouts related to disaster preparedness and educational opportunities. In addition, personal preparedness plan brochures were distributed from the ready.gov website (http://www.fema.gov/medialibrary/assets/documents/34330)

There were seven learning outcomes for the nursing students who participated in the pilot program. Table 1.1 below outlines the teaching plan for the educational intervention.

Table 1.1. Learning Outcomes and Teaching Plan

\begin{tabular}{|l|l|l|l|}
\hline \multicolumn{1}{|c|}{$\begin{array}{c}\text { Learning } \\
\text { Outcomes }\end{array}$} & \multicolumn{1}{|c|}{ Content } & $\begin{array}{c}\text { Teaching } \\
\text { Methods }\end{array}$ & Evaluation \\
\hline Define & $\begin{array}{l}\text { Present different disaster } \\
\text { definitions from various } \\
\text { professional organizations. } \\
\text { Discuss various types of } \\
\text { disaster's and their } \\
\text { prevalence. } \\
\begin{array}{l}\text { List examples of disasters } \\
\text { and the consequences } \\
\text { experienced by communities. }\end{array}\end{array}$ & $\begin{array}{l}\text { Lecture, slides } \\
\text { and handouts }\end{array}$ & Course evaluation \\
& & & \\
\hline
\end{tabular}




\begin{tabular}{|c|c|c|c|}
\hline $\begin{array}{l}\text { Describe the } \\
\text { importance of } \\
\text { personal } \\
\text { preparedness } \\
\text { and create an } \\
\text { individualized } \\
\text { plan. }\end{array}$ & $\begin{array}{l}\text { Present examples of when } \\
\text { personal preparedness plans } \\
\text { can be utilized. } \\
\text { Discuss evidence supporting } \\
\text { medical professionals having } \\
\text { a personal preparedness plan. } \\
\text { Provide tools for students to } \\
\text { develop a personal } \\
\text { preparedness plan. }\end{array}$ & $\begin{array}{l}\text { Slides, lecture, } \\
\text { and questions to } \\
\text { stimulate } \\
\text { discussions } \\
\text { regarding } \\
\text { importance of } \\
\text { personal } \\
\text { preparedness. } \\
\text { Personal } \\
\text { preparedness } \\
\text { plan template } \\
\text { printed from } \\
\text { ready.gov } \\
\text { website }\end{array}$ & $\begin{array}{l}\text { Course evaluation } \\
\text { and post survey } \\
\text { results }\end{array}$ \\
\hline $\begin{array}{l}\text { List major } \\
\text { public health } \\
\text { threats that } \\
\text { could require a } \\
\text { disaster } \\
\text { response effort. }\end{array}$ & $\begin{array}{l}\text { Identify public health events } \\
\text { in the past the have required } \\
\text { a response effort from } \\
\text { medical professionals. }\end{array}$ & $\begin{array}{l}\text { Slides, lecture, } \\
\text { discussion } \\
\text { questions }\end{array}$ & Course evaluation \\
\hline $\begin{array}{l}\text { Identify } \\
\text { professional } \\
\text { roles and } \\
\text { responsibilities } \\
\text { of a nurse } \\
\text { responding to a } \\
\text { public health } \\
\text { emergency. }\end{array}$ & $\begin{array}{l}\text { Identify various roles and } \\
\text { responsibilities of nursing } \\
\text { professionals related to } \\
\text { disasters. } \\
\text { Illustrate the need for } \\
\text { nursing professionals to be } \\
\text { involved in disaster } \\
\text { preparedness. } \\
\text { Identify how roles change in } \\
\text { different settings (e.g., public } \\
\text { health nurse vs. acute care } \\
\text { nurse). }\end{array}$ & $\begin{array}{l}\text { Case studies } \\
\text { with discussion } \\
\text { questions } \\
\text { challenging } \\
\text { students to } \\
\text { identify } \\
\text { professional } \\
\text { roles and } \\
\text { responsibilities, } \\
\text { slides }\end{array}$ & $\begin{array}{l}\text { Course evaluations, } \\
\text { and response to } \\
\text { cases study } \\
\text { questions }\end{array}$ \\
\hline
\end{tabular}




\begin{tabular}{|l|l|l|l|}
\hline $\begin{array}{l}\text { Discover } \\
\text { ethical and } \\
\text { legal } \\
\text { considerations } \\
\text { through case } \\
\text { study } \\
\text { discussions. }\end{array}$ & $\begin{array}{l}\text { Present liability laws that are } \\
\text { relevant to responding during } \\
\text { a medical emergency. }\end{array}$ & $\begin{array}{l}\text { Case studies } \\
\text { present potential changes in } \\
\text { with discussion practice during } \\
\text { questions } \\
\text { sertaining to } \\
\text { scope of practice allowed by } \\
\text { different ethical } \\
\text { and legal } \\
\text { considerations, } \\
\text { slides, handouts } \\
\text { of liability laws }\end{array}$ & $\begin{array}{l}\text { Course evaluations } \\
\text { and case study } \\
\text { question answers. }\end{array}$ \\
\hline $\begin{array}{l}\text { order). } \\
\text { opportunities } \\
\text { for continuing } \\
\text { education. }\end{array}$ & $\begin{array}{l}\text { Share opportunities to } \\
\text { receive more education } \\
\text { regarding disaster } \\
\text { preparedness. }\end{array}$ & $\begin{array}{l}\text { Slides, lecture, } \\
\text { handouts of } \\
\text { opportunities }\end{array}$ & $\begin{array}{l}\text { Evaluation based on } \\
\text { increased } \\
\text { participation in } \\
\text { education regarding } \\
\text { disaster as } \\
\text { evidenced by post- } \\
\text { survey }\end{array}$ \\
\hline $\begin{array}{l}\text { Identify ways } \\
\text { to volunteer } \\
\text { before, during } \\
\text { and after a } \\
\text { disaster. }\end{array}$ & $\begin{array}{l}\text { List current opportunities for } \\
\text { volunteering. }\end{array}$ & $\begin{array}{l}\text { Slides, lecture, } \\
\text { handout of } \\
\text { opportunities }\end{array}$ & $\begin{array}{l}\text { Evaluation based on } \\
\text { increased } \\
\text { registration with } \\
\text { volunteer medical } \\
\text { organizations as } \\
\text { evidenced by post- } \\
\text { survey }\end{array}$ \\
\hline
\end{tabular}

\section{Organizational/Systems' Factors}

The setting of the pre-survey, course and evaluation were convenient to both the participants and the investigator. Participating students, however, were not given additional time to complete the above items.

One potential barrier was identified related to the post-survey. This survey took approximately five minutes to complete and was delivered via e-mail. This delivery method and the time needed to complete the survey created the potential for a decreased number of respondents. The follow-up reminder e-mail helped minimize this barrier; but the investigator still anticipated a larger number of pre-surveys than post-surveys. Students were reminded that 
all surveys and evaluations would remain anonymous, that participation was voluntary, and that no course grades would be affected. This promoted participation without fear of retribution.

Due to the limited amount of literature specifically addressing nursing student education about emergency preparedness, the investigator had to use a combination of sources to develop content. Class information and complimentary materials were derived from both a content expert at the Rhode Island Department of Health and sources such as the Center for Disease Control and Prevention.

\section{Procedures}

The proposal for an educational program on emergency preparedness, including the three-question surveys and class evaluation tool, was submitted to the IRB for review. Once exempt status was conferred by the IRB, course content was developed including power point presentation slides with notes, case studies, and handouts. Final course content and the teaching plan were sent to the professor for approval to use in her class, and a date was identified to educate nursing students on emergency preparedness and response.

On the date of the presentation, the investigator introduced herself to the students and gave a five-minute introduction to the education project. A three-question, anonymous survey was then distributed to all nursing students present in the class. Students were also asked to voluntarily provide an email address on a separate piece of paper that was later used to send the post-survey (see Appendix C). Attached to the pre-survey was an informational letter re-iterating that participation in the educational program and surveys was optional and in no way would affect course grades (see Appendix D). Implied understanding of the program and it's risks and benefits was assumed through completion of the pre-survey. Completed pre-surveys were collected by the investigator and placed in a sealed envelope to ensure confidentiality.

After collection of the surveys, the nursing students engaged in a 60-minute educational session utilizing lecture, group discussion, case studies, and opportunities for questions. An evaluation tool that used a 5-point Likert scale was administered to evaluate the presenter and 
content. The evaluation form had no student identifiers and was collected by the investigator. The researcher thanked both the students and the professor for their time and participation and stated that the students who provided an e-mail address would be receiving a post-survey in three weeks. The investigator's contact information was provided to students in case any questions arose after the educational session.

Three weeks after the intervention, the investigator sent an e-mail message to all students who provided addresses, asking them to complete the post-survey via an attached link (see Appendix E). It was re-stated in the e-mail message that participation was optional and to expect a reminder e-mail in one week. The researcher's contact information was listed with instructions to call or send a message if the participating student wished to be taken off of the contact list. Exactly one week later, or four weeks following the intervention, a second e-mail message was sent to all provided addresses (see Appendix F). To maintain survey confidentiality, there were no identifiers that allowed the investigator to recognize which students had already completed the survey, so the reminder was sent to all e-mail addresses. The investigator's contact information was listed again and it was restated that participation was optional and that the request should be disregarded if the survey had already been completed.

Following collection of the surveys, information was reviewed, organized and analyzed using basic Microsoft Excel calculations. To maintain confidentiality, all student surveys, evaluations and e-mail addresses were stored in a sealed envelope and placed in a locked cabinet at the Rhode Island College School of Nursing.

\section{Ethical Considerations}

There were minimal ethical concerns for this pilot educational program and the IRB determined that the program was exempt from federal research regulations. There was no risk of physical harm to any participants. The class content was deemed to have minimally disturbing material and images regarding disasters and the effects of disasters. Students were notified of this potential prior to the start of the class. All risks and benefits were disclosed to participants 
through an informational letter prior to initiating the pre-survey. There was a slight risk that students may fear retribution from the professor for not participating in the program and/or surveys. The informational letter explicitly stated that the student's course grades would not be affected by their decision regarding participation in the program. In addition, all surveys and evaluations remained confidential and students e-mail addresses were kept in a locked cabinet to ensure confidentiality. Students were informed that participation was strictly voluntary and uncompensated, and that they could withdraw from participation at any time. Consent was considered implied through participation in the surveys. The investigator's contact information was provided to students in case they had questions or comments about the education.

\section{Measurement}

The investigator designed both the pre- and post-surveys to describe the effects of the educational intervention on nursing students' willingness to participate in personal disaster preparedness and to volunteer during a public health emergency. The pre- and post-surveys consisted of close-ended "yes" or "no" questions, with space for free text on question three to provide further information if a student answered "yes." The answers to the survey questions provided the researcher with information regarding whether personal preparedness plans were made following the intervention. The free text allowed the identification of barriers to making personal preparedness plans and to responding to a public health emergency.

\section{Data Analysis}

Descriptive statistical analysis was used to describe the answers to the "yes /no" questions. The percentages of students answering "yes" vs. "no" were calculated for each of the

pre- and post-survey questions and then compared to each other. Free text answers were reviewed to identify common themes. Reliability was ensured by use of closed-ended questions. The survey clearly measured whether there was an increase in individual preparedness plans and 
willingness to respond, supporting the validity of the survey. In addition, the students evaluated the educational intervention using a 5-point Likert scale. This evaluation measured the perceived benefit of the class content, the teaching strategies used, and the presenter's ability to enhance learning through facilitated discussion and presentation of pertinent concepts. Information from the evaluation was considered in assessing the overall effect of the educational session. 


\section{Intervention Evaluation}

A voluntary class evaluation was administered to participants following the completion of the one-hour didactic intervention. The evaluation was divided into three parts. The first two portions asked the students to rate how well each learning objective was met and then to rate the presenter and teaching strategies employed. Both portions of the evaluation utilized a 5-point Likert scale. The third aspect of the evaluation was an optional free text area that asked for any comments or suggestions. Eighteen students participated in the intervention and returned course evaluations. Of the 18 evaluations submitted, all questions utilizing the Likert scale were answered.

With the exception of one respondent on one learning objective, all students answered positively (score of 4-agree or 5-strongly agree) that the learning objectives were appropriately addressed and met through the intervention. The one exception was in response to the learning objective "List opportunities for continuing education," one student answered that they "neither agree nor disagree." The learning objective with the lowest mean score of 4.6 was "Discover ethical and legal considerations for a nurse during a disaster." The highest mean score of 4.8 was shared by three learning objectives to "Describe the importance of personal preparedness and explain how to create an individualized plan," "Identify professional roles and responsibilities of a nurse responding to a public health emergency" and "Identify ways to volunteer before, during and after a disaster." Table 1.2 illustrates the students' evaluation of how well they achieved program-learning outcomes.

Table 1.2. Program Evaluation, Learning Outcomes

\begin{tabular}{|c|c|c|c|c|c|c|}
\hline $\begin{array}{c}\text { Learning } \\
\text { Outcomes }\end{array}$ & $\begin{array}{c}\text { Mean } \\
\text { Score }\end{array}$ & $\begin{array}{c}\text { Strongly } \\
\text { Disagree } \\
(1)\end{array}$ & $\begin{array}{c}\text { Disagree } \\
(2)\end{array}$ & $\begin{array}{c}\text { Neither } \\
\text { Agree nor } \\
\text { Disagree } \\
(3)\end{array}$ & $\begin{array}{c}\text { Agree } \\
(4)\end{array}$ & $\begin{array}{c}\text { Strongly Agree } \\
\text { (5) }\end{array}$ \\
\hline Define Disasters & \multirow{4.7}{*}{} & $\mathbf{0}$ & $\mathbf{0}$ & $\mathbf{0}$ & $\mathbf{5}$ & $\mathbf{1 3}$ \\
\cline { 3 - 7 } & & $\mathbf{0 \%}$ & $\mathbf{0 \%}$ & $\mathbf{2 8 \%}$ & $\mathbf{7 2 \%}$ \\
\hline
\end{tabular}




\begin{tabular}{|c|c|c|c|c|c|c|}
\hline \multirow{2}{*}{$\begin{array}{c}\text { Describe the } \\
\text { importance of } \\
\text { personal } \\
\text { preparedness } \\
\text { and explain how } \\
\text { to create an } \\
\text { individualized } \\
\text { plan }\end{array}$} & \multirow[t]{2}{*}{4.8} & 0 & 0 & 0 & 3 & 15 \\
\hline & & $0 \%$ & $0 \%$ & $0 \%$ & $17 \%$ & $83 \%$ \\
\hline \multirow{2}{*}{$\begin{array}{c}\text { List major } \\
\text { public health } \\
\text { threats that } \\
\text { could require a } \\
\text { disaster } \\
\text { response effort }\end{array}$} & \multirow[t]{2}{*}{4.7} & 0 & 0 & 0 & 5 & 13 \\
\hline & & $0 \%$ & $0 \%$ & 0\% & $28 \%$ & $72 \%$ \\
\hline \multirow{2}{*}{$\begin{array}{l}\text { Identify } \\
\text { professional } \\
\text { roles and } \\
\text { responsibilities } \\
\text { of a nurse } \\
\text { responding to a } \\
\text { public health } \\
\text { emergency }\end{array}$} & \multirow[t]{2}{*}{4.8} & 0 & 0 & 0 & 4 & 14 \\
\hline & & $0 \%$ & $0 \%$ & $0 \%$ & $22 \%$ & $78 \%$ \\
\hline \multirow{2}{*}{$\begin{array}{l}\text { Discover ethical } \\
\text { and legal } \\
\text { considerations } \\
\text { for a nurse } \\
\text { during a } \\
\text { disaster } \\
\end{array}$} & \multirow[t]{2}{*}{4.6} & 0 & $\mathbf{0}$ & 0 & 8 & 10 \\
\hline & & $0 \%$ & $0 \%$ & $0 \%$ & $44 \%$ & $56 \%$ \\
\hline \multirow{2}{*}{$\begin{array}{c}\text { List } \\
\text { opportunities } \\
\text { for continuing } \\
\text { education }\end{array}$} & \multirow[t]{2}{*}{4.7} & 0 & 0 & 1 & 3 & 14 \\
\hline & & $0 \%$ & $0 \%$ & $5 \%$ & $17 \%$ & $78 \%$ \\
\hline \multirow{2}{*}{$\begin{array}{l}\text { Identify ways to } \\
\text { volunteer } \\
\text { before, during } \\
\text { and after a } \\
\text { disaster }\end{array}$} & \multirow[t]{2}{*}{4.8} & 0 & 0 & 0 & 4 & 14 \\
\hline & & $0 \%$ & $0 \%$ & $0 \%$ & $22 \%$ & $78 \%$ \\
\hline
\end{tabular}

All students responded positively (either "agreed" or "strongly agreed") that both the "Presenter was knowledgeable about the topic" and "The presenter utilized appropriate teaching strategies to meet course objectives." Both questions received a mean score of 4.9. Table 1.3 illustrates the second section of the program evaluation data analysis.

Table 1.3. Program Evaluation, Presenter and Teaching Strategies 


\begin{tabular}{|c|c|c|c|c|c|c|}
\hline & $\begin{array}{c}\text { Mean } \\
\text { Score }\end{array}$ & $\begin{array}{c}\text { Strongly } \\
\text { Disagree } \\
(1)\end{array}$ & $\begin{array}{c}\text { Disagree } \\
(2)\end{array}$ & $\begin{array}{c}\text { Neither } \\
\text { Agree nor } \\
\text { Disagree (3) }\end{array}$ & $\begin{array}{c}\text { Agree } \\
(4)\end{array}$ & $\begin{array}{c}\text { Strongly } \\
\text { Agree (5) }\end{array}$ \\
\hline $\begin{array}{c}\text { The presenter } \\
\text { was } \\
\text { knowledgeable } \\
\text { about the topic }\end{array}$ & $\mathbf{4 . 9}$ & $\mathbf{0}$ & $\mathbf{0}$ & $\mathbf{0}$ & $\mathbf{2}$ & $\mathbf{1 6}$ \\
\cline { 2 - 7 } & $\mathbf{0 \%}$ & $\mathbf{0 \%}$ & $\mathbf{0 \%}$ & $\mathbf{1 1 \%}$ & $\mathbf{8 9 \%}$ \\
\hline $\begin{array}{c}\text { The presenter } \\
\text { utilized } \\
\text { appropriate } \\
\text { teaching } \\
\text { strategies to } \\
\text { meet course } \\
\text { objectives }\end{array}$ & $\mathbf{4 . 9}$ & $\mathbf{0}$ & $\mathbf{0}$ & $\mathbf{0}$ & $\mathbf{1}$ & $\mathbf{1 7}$ \\
\cline { 2 - 7 } & $\mathbf{0 \%}$ & $\mathbf{0 \%}$ & $\mathbf{0 \%}$ & $\mathbf{5 \%}$ & $\mathbf{9 4 \%}$ \\
\hline
\end{tabular}

Six of the 18 students wrote a comment in the optional portion of the course evaluation. Five of the comments were positive, while one student expressed confusion regarding a statistic discussed during the course. All comments are listed below in table 1.4.

Table 1.4. Program Evaluation, Free Text Comments

\begin{tabular}{|c|}
\hline "Very interesting + informative presentation." \\
\hline "I'm going home with a plan to make a plan. Thank you!" \\
\hline "If 8 million people lost power during Hurricane Sandy, how could only 800,000 people be \\
affected by disasters in the U.S. a year? Confused by this statistic" \\
"Great presentation. Very thorough and engaging." \\
"Very good presentation" \\
\hline "Great job" \\
\hline
\end{tabular}

\section{Pre/Post Survey Results}

Prior to the start of the educational intervention, a pre-survey consisting of three questions was administered and collected. There was one student who was absent on the day of the intervention, resulting in 18 students eligible to participate. All students completed and 
returned a pre-survey. Table 1.5 illustrates the results of the pre-survey.

\section{Table1.5 Pre-Survey Results $(n=18)$}

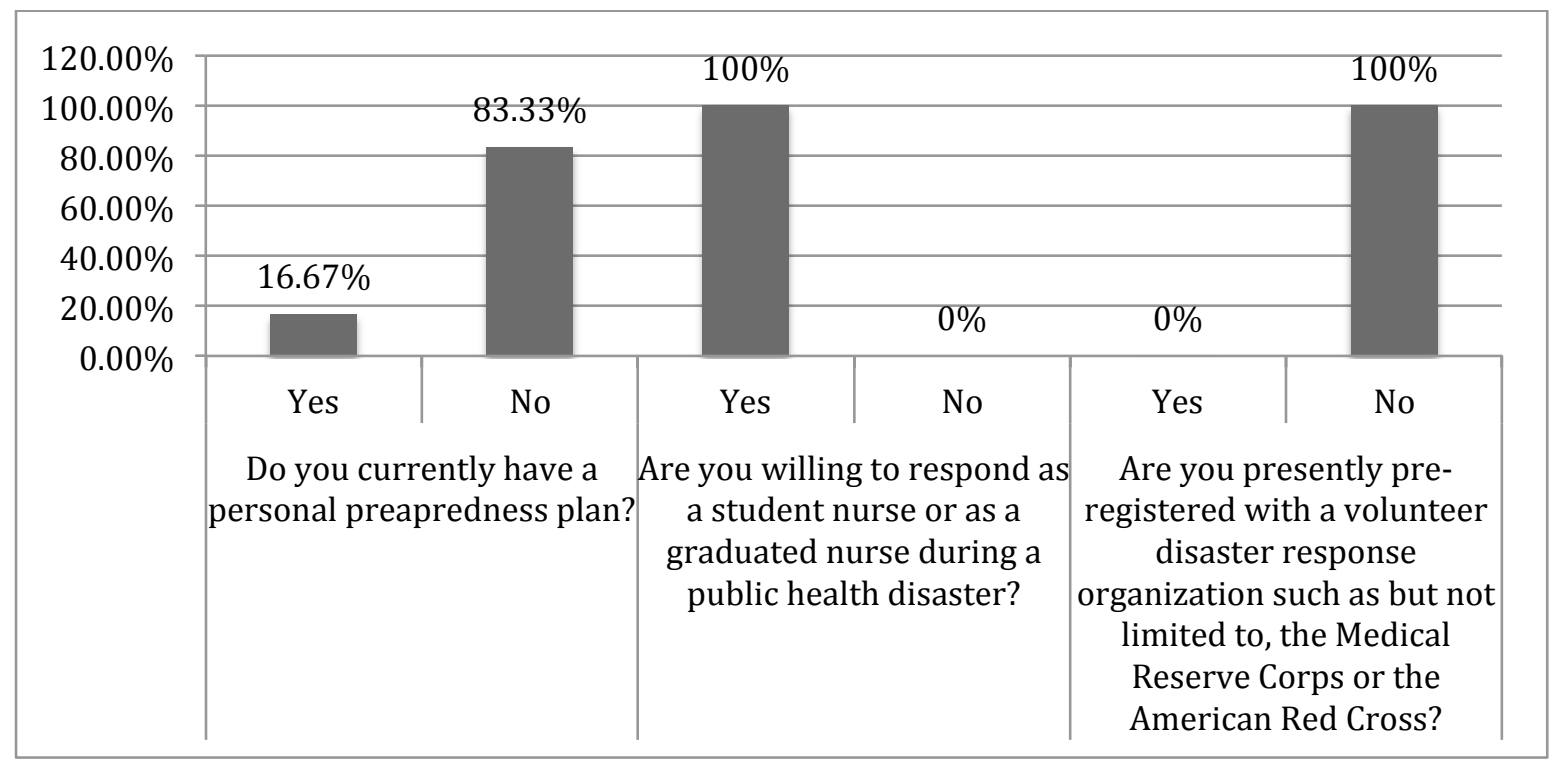

As can be seen, a vast majority of the students $(83.33 \%, n=15)$ reported not having a personal preparedness plan prior to the start of the education. Despite this lack of a personal plan, all students stated a willingness to respond as either a student or graduated nurse in the case of a public health emergency. The third question revealed that none of the students were currently pre-registered with a disaster response organization.

At the conclusion of the class, students were asked for an email address so that a postsurvey link could be sent to them. Seventeen of the 18 students who participated in the course intervention provided their e-mail address. All 17 students who provided their e-mail addresses received a message two weeks following the intervention. Eight students responded to the postsurvey following the first e-mail request and six students responded to the survey following the second request, resulting in $78 \%(\mathrm{n}=14)$ of the students participating in the post-survey. The post-survey consisted of the same three questions as the pre-survey. Table 1.6 illustrates the responses to the post-survey.

Table 1.6. Post-Survey Results $(n=14)$ 


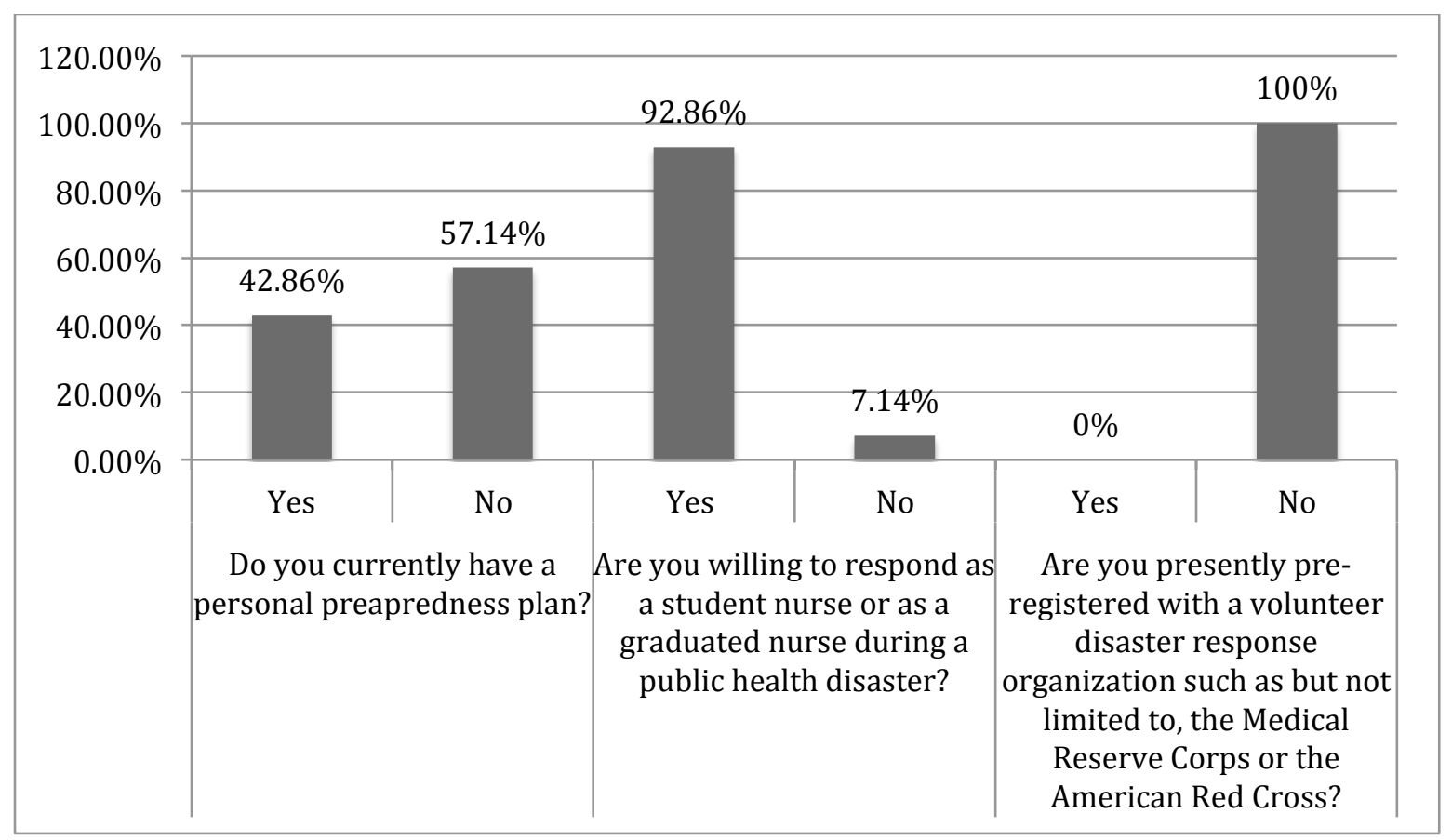

The post-survey results revealed an increase in the number of students who had a personal preparedness plan from $16.67 \%(n=3)$ to $42.86 \%(n=6)$. Following the intervention there was a slight decrease in the number of students willing to respond during a public health emergency, as one student responded "no" to the second question. Of note, the student who responded "no" to being willing to respond during a public health emergency responded,"yes" to having a personal preparedness plan. There was no change in the results of the third question as $100 \%$ responded that they were not registered with a disaster response organization.

\section{Summary and Conclusions}

Disaster preparedness and response in the United States will continue to be an important topic for discussion, as the high rate of disasters is expected to continue in the coming years. Representing the largest number of health care workers in the United States (AACN, 20110), and working in a variety of settings, nurses play a crucial role in ensuring that the nation is ready to respond to disasters. Disaster response, however, can be challenging and nurses need to develop the required knowledge, skills and attitudes prior to a disaster striking.

A literature review revealed common barriers that hinder nurses from responding to 
disasters. Barriers identified included fears of contracting contagious diseases, lack of safety during a response effort, safety concerns for the responder's family, and legal and ethical issues. Some studies revealed a lack of nursing knowledge regarding disasters in general. The literature further suggested that disaster response training should be incorporated into nursing school curricula in order to combat the above-mentioned barriers. Overall, the literature suggested that nurses were unprepared to perform essential roles and responsibilities during times of extreme emergencies,

Based on the barriers identified in the literature and the need to incorporate disaster preparedness into nursing school curricula, a pilot educational program plan was developed to introduce the topic of disaster preparedness to senior-level nursing students. The purpose of the project was to determine if a disaster preparedness educational intervention for nursing students would increase both, engagement in personal preparedness, and in a willingness to respond during a public health emergency.

The program plan was designed utilizing both an ecological model and constructivist learning theory to guide teaching strategies. Program content was developed using the National League for Nursing's Excellence in Nursing Education Model, along with recommendations from state and national disaster planning organizations.

The intervention for this pilot program plan was presented to senior nursing students enrolled in one section of the Public and Community Health Nursing course. At the time of the intervention, 18 students were present and voluntarily participated in the education. A presurvey, asking three questions related to disaster preparedness, was administered and all 18 students completed the survey. A one-hour class that covered the topics of personal preparedness, potential threats, professional obligations, ethical and legal considerations, volunteer disaster organizations and continuing education opportunities followed. A variety of teaching methods were used; including lecture, case study discussions, and informational handouts.

Following completion of the educational program, students were asked to complete an 
evaluation that measured how well the learning outcomes were achieved, and the efficacy of the presenter's knowledge and teaching strategies. The students were also asked to supply their email addresses so that a follow-up survey could be administered. Seventeen students provided their e-mail addresses and were sent two reminder emails with a Survey Monkey link to complete a post-survey. The e-mail reminders were sent two weeks and three weeks after the intervention. A total of 14 students (78\%) completed the post-survey. The post-survey consisted of the same three questions as the pre-survey. The results of the pre- and post-surveys were analyzed and compared to see if the program intervention resulted in increased student engagement in disaster preparedness and increased willingness to respond.

To gauge the effectiveness of the educational intervention, the pre- and post-survey questions were compared. The most significant change was seen in the first question "Do you currently have a personal preparedness plan?” The idea of personal preparedness was emphasized during the class, under the assumption that volunteers who have a personal preparedness plan will be more willing to respond during a disaster, because they sense that they and their family will be safe. As part of the education, handouts were provided to students to guide them in making a personal preparedness plan. The pre- and post-survey results affirmed the benefit of nursing student education, as the number of nursing students who had a personal preparedness plan increased from $16.67 \%(n=3)$ to $42.86 \%(n=6)$ following the intervention. This finding is consistent with the course evaluation where the learning outcome "Describe the importance of personal preparedness and explain how to create an individualized plan" had the highest mean score of 4.8 , indicating that the learning objective was covered well during the class.

Another expected outcome of the educational intervention was that there would be a higher rate of nursing students who were willing to respond during a public health emergency. The second question on the pre/post surveys addressed this issue by asking "Are you willing to respond as a student nurse or as a graduated nurse during a public health disaster?" 
Unexpectedly, $100 \%(n=18)$ of the students answered "yes" on the pre-survey, in contrast to the literature which reported that nurses and students had many barriers to responding to public health emergencies. Even more surprising, there was a slight decrease in the willingness to respond on the post-survey, as only $92.96 \%(\mathrm{n}=13)$ responded "yes" and $7.14 \%(\mathrm{n}=1)$ responded "no." Unfortunately, there is no information available to explain the reason for this change in response. It is possible that the student who responded "yes" on the pre-survey, responded "no" on the post-survey after learning about what disaster preparedness and response requires. Another potential reason could be a simple mistaken entry on either the pre- or post-surveys.

The third question on the pre- and post-survey asked "Are you presently pre-registered with a volunteer disaster response organization such as, but not limited to, the Medical Reserve Corps or the American Red Cross?" There was no change in student responses after the class, as 18 students (100\%) on the pre-survey answered "no" and 14 students (100\%) answered "no" afterwards. These results highlight a need to emphasize the importance of pre-registering with a professional organization prior to a disaster striking. One theme identified in the literature was the ineffectiveness of "spontaneous volunteers," or volunteers who simply show up the moment a disaster strikes, and the benefit of having volunteers that are pre-registered and previously credentialed (Peterson, 2006). This topic was addressed during the class with the learning outcome "Identify ways to volunteer before, during and after a disaster." All students agreed that the learning objective was sufficiently addressed with a mean score of 4.8 . This indicates a need to further explore barriers to nursing student preregistration with an organization, such as the multiple, competing demands faced by these graduating seniors.

The course evaluation was used to measure how the content was delivered and if all the learning outcomes were appropriately addressed. All students replied positively (either agreed or strongly agreed) that six of the seven learning objectives were met. The learning outcome "List opportunities for continuing education" had the vast majority $(95 \%, \mathrm{n}=17)$ of students agree that 
the learning objective was met, while one student neither "agreed nor disagreed." This could indicate that this learning outcome could be addressed with more detail in future courses. The second portion of the course evaluation revealed that all students felt the presenter was knowledgeable and utilized appropriate teaching strategies. The optional comments on the course evaluations reflected positive student perceptions, with many saying that the class was engaging and interesting.

Overall, the educational intervention had the desired outcome of an increased number of students reporting that they had a personal preparedness plan. Another expected outcome that all students would be willing to respond to a disaster was reported before the intervention, but one of the students changed her mind about responding after the class.

There were a number of limitations to this pilot educational program. First is the small sample size of only 18 students participating in the intervention and pre-survey, followed by 14 students responding to the post-survey. A larger sample of students may have shown different outcomes. The post-survey sample size could have been negatively impacted by the students' imminent graduation from nursing school, which would limit their amount of free time and willingness to complete the survey. This factor could also influence the survey results, specifically the third question related to pre-registering with a professional organization. Given the amount of work expected of a senior nursing student, and other factors such as study for the nursing boards, registering with a volunteer organization may not have been a top priority for them. Further studies could evaluate the effectiveness of this educational intervention at a different point during nursing school, or simply ask the post-survey questions after the students had graduated and taken their nursing boards.

The third limitation was that no information regarding the students' past experience with disasters was requested on the surveys. One student in the class, however, reported being an Emergency Medical Technician who had responded to disasters in the past. For future studies, it may be helpful to determine the extent of past experiences to see if that affects willingness to respond. A final limitation to this investigation was that participating students had other disaster- 
related assignments to complete for the Public and Community Health Nursing course after the intervention, but before the post-survey. The students all participated in a mock emergency medication distribution exercise and were required to read a textbook chapter on disaster preparedness. Either of these assignments could have influenced the post-survey results. 


\section{Recommendations and Implications}

The results of this pilot educational program are consistent with common themes found throughout the literature. Findings from this investigation highlight the fact that many nursing students want to respond during a public health emergency, however, they don't know how to respond (Veenem 2006), and may feel unprepared for their roles and responsibilities during a disaster. (Baack \& Alfred 2013). Nurses have the opportunity to affect the health of a majority of the population due to the extensive and diverse areas in which they work. Advanced practice public health nurses, therefore, need to conduct further studies to determine the best methods for educating and training students and nurses to prepare for, and respond to, public health emergencies. Additional research is needed to evaluate past nursing experiences during disasters to determine the most efficient and effective practices. Another area for investigation is nurses' perceptions and misperceptions about disaster preparedness, and the barriers that prevent them from responding. Addressing these research issues can help identify best practices for nurses and students when faced with the choice of whether or not to respond during a disaster, and ultimately, result in a more resilient community.

One of the major challenges of disaster preparedness is the need for ongoing education and training so that responders have the required knowledge and skills to deal with constantly changing and evolving threats. Education of nurses, therefore, needs to be a continuous and ongoing process to ensure the best response during a public health threat. Advanced practice registered nurses (APRN) need to collaborate with members of other disciplines to develop, implement and evaluate continuing education programs and training exercises for interdisciplinary disaster response teams. Education must include ways to work with vulnerable, diverse populations who have special needs that must be met due to age, condition, disability, or 
language barrier. In addition, education regarding ethical dilemmas that frequently present during a disaster response need to be thoroughly integrated throughout continuing education programs.

The need to educate nurses is clearly evident and the best time to start that education is early in the nurse's career. Starting that education in nursing schools is identified as a best practice; but this requires a significant amount of curriculum development and change.

Curriculum change is a role for public health nurses with advanced degrees who can advocate for the integration of emergency preparedness and response content, as well as clinical practice, into undergraduate curricula. Further studies are needed to help identify the best methods for delivering emergency preparedness content. In addition, one study reviewed in the literature polled deans of nursing programs and found that $74 \%$ of participating deans did not feel their nursing educators had the expertise to teach emergency preparedness content (Weiner et al., 2005). This indicates a need for further studies on how to develop the knowledge of present educators about the topic, and how to maintain their competency as threats rapidly and constantly change.

The benefits of a comprehensive approach to education are evident in the study by Culley (2010), which described a university that required their nursing students to become active members of the university's Medical Reserve Corps (MRC. Following the example of the university-based MRC noted above, Rhode Island College nursing faculty have a unique opportunity to partner with this small state's one Department of Health (DOH) and one Medical Reserve Corps (MRC) in educating and training interdisciplinary groups of students in disaster preparedness and response. The benefits of this partnership would include students having hands-on experience with disaster preparedness, which would likely support them in staying active with the MRC once they graduate.

Implications of this literature review and pilot program further suggest recommendations for how to educate and train nurses who have already graduated from nursing school. Advanced practice nurses can lead in the use of innovative technologies for education and training via on- 
line courses, high fidelity simulations and advanced communication systems. They can also direct others to access resources, such as informational websites available through both the Center for Disease Control and Prevention (CDC) and the Federal Emergency Management Agency (FEMA). In addition, they can foster knowledge of employer disaster policies and plans and facilitate skills training exercises at their worksites.

Another responsibility for advanced practitioners is to encourage pre-registration of all healthcare professionals with the national databases of response volunteers that are currently underutilized. In preparation for registration, advanced practice nurses can lead others in personal and professional preparedness planning, so that they have a plan for themselves and their family first. As the ecological model demonstrates, personal preparedness plans directly affects how well employer plans will work, which ultimately affects the resilience of the community to respond to a disaster.

Advance practice nurses have a professional responsibility to lead emergency preparedness initiatives. Their critical thinking skills, nursing process, and various backgrounds and experiences can be applied to all phases of disasters. They can help to identify gaps in preparedness for special populations, as well as provide education to a diverse population. Roles for advance practice nurses should include consulting with emergency management organizations, community agencies and aggregates; applying their clinical expertise to disaster preparedness. For example, a pediatric APRN would be well-suited to consult with schools, a gerontology nurse with nursing homes, and a global health nurse with immigrant clinics to help prepare for disasters.

Nurses are on the front lines in combating the negative effects of disasters, they are willing to respond, yet often lack the appropriate knowledge and skills for an effective response. This limits their ability to save lives and increases the probability of chaos within a disaster zone. Incorporating the specialty of disaster nursing into the curriculum will help to promote personal preparedness and an effective professional response. Making disaster readiness a professional obligation of nursing must be a priority! 


\section{References}

Adams, L., \& Canclini, S. (2008). Disaster readiness: A community-university partnership. Online Journal of Issues in Nursing, 13(3). Retrieved from http://www.nursingworld.org/MainMenuCategories/ANAMarketplace/ANAPeriodicals/ OJIN/TableofContents/vol132008/No3Sept08/ArticlePreviousTopic/DisasterReadiness.ht $\mathrm{ml}$

Adams, R. F., Ayer, A. C., \& Bishop, L. R. (2011). Arming campus police: Managing the risk [Entire issue]. University Risk Management and Insurance Association Journal. 
Retrieved from http://www.nkms.com/uploadcache/1315496358-

AdamsAyerBishop_ArmingCampusPolice_FINAL_20110718.pdf

American Association of Colleges of Nursing. (2008). The essentials of baccalaureate education for professional nursing practice. Retrieved from American Association of Colleges Of Nursing: http://www.aacn.nche.edu/education-resources/baccessentials08.pdf

American Nurses Association. (2010). Who will be there? Ethics, the law, and a nurse's duty to respond in a disaster [issue brief]. Retrieved from Nursing World: http://www.nursingworld .org/MainMenuCategories/Policy-Advocacy/Positions-andResolutions/Issue-Briefs/Disaster-Preparedness.pdf

American Public Health Association. (2006, November 8). Response to disasters protection of rescue and recovery workers volunteers and residents responding to disasters [Policy statement 20069]. Retrieved from http://www.apha.org/advocacy/policy/policysearch/default.htm?id=1333:

Baack, S., \& Alfred, D. (2013). Nurses' preparedness and perceived competence in managing disasters. Journal Of Nursing Scholarship, 45(3), 281-287. http://dx.doi.org/10.1111/jnu.12029

Beaton, R., Bridges, E., Salazar, M. K., Oberle, M. W., Stergachis, A., Thompson, J., \& Butterfield, P. (2008). Ecological model of disaster management. AAOHN Journal: Official Journal Of The American Association Of Occupational Health Nurses, 56(11), 471-478.

Bergeron, S. M., Cameron, S., Armstrong-Strassen, M., \& Pare, K. (2006). Diverse implications of a national health crisis: A qualitative exploration of community nurses' SARS experiences. Canadian Journal Of Nursing Research, 38(2), 42-54.

Brandon, A. F., \& All, A. C. (2010). Constructivism theory analysis and application to curricula. Nursing Education Perspectives, 31(2), 89-92. 
Brewer, K. (2010). Who will be there? Ethics, the law, and a nurse's duty to respond in a disaster. Retrieved from http://www.nursingworld.org/MainMenuCategories/PolicyAdvocacy/Positions-and-Resolutions/Issue-Briefs/Disaster-Preparedness.pdf

Bronfenbrenner, U. (1977). Toward an experimental ecology of human development. American Psychologist, 32(7), 513-531. http://dx.doi.org/10.1037/0003-066X.32.7.513

Bulson, J. A., \& Bulson, T. (2011). Nursing process and critical thinking linked to disaster preparedness. JEN: Journal Of Emergency Nursing, 37(5), 477-483. http://dx.doi.org/10.1016/j.jen.2010.07.011

Buyum, A., Dubruiel, N., Torghele, K., Alperin, M., \& Miner, K. R. (2009). Can summits lead to curricula change? An evaluation of emergency preparedness summits for schools of nursing in Georgia. Journal Of Continuing Education In Nursing, 40(5), 210-215. http://dx.doi.org/10.3928/00220124-20090422-04

Center for Disease Control and Prevention. (2010). Strengthening the nation's emergency response state by state; A report on CDC-funded preparedness and response activities in 50 States, 4 Cities, and 8 U.S. insular areas. Retrieved from Center for Disease Control and Prevention: http://www.cdc.gov/phpr/publications/2010/phprep_report_2010.pdf

Center for Disease Control and Prevention. (2012). Strategic National Stockpile (SNS). Retrieved from Center for Disease Control and Prevention: http://www.cdc.gov/phpr/stockpile/stockpile.htm

Chikotas, N. E. (2008). Theoretical links supporting the use of problem-based learning in the education of the nurse practitioner. Nursing Educational Perspectives, 29(6), 359-362.

Culley, J. M. (2010). The role of the medical reserve corps in nursing education. Journal Of Nursing Education, 49(12), 708-711. http://dx.doi.org/10.3928/01484834-20100930-04 Dahlberg, L. L., \& Krug, E. G. (2002). Violence-a global public health problem []. Retrieved from http://www.cdc.gov/violenceprevention/overview/social-ecologicalmodel.html 
Federal Emergency Management Agency. (2011). National preparedness goal. Retrieved from : http://www.fema.gov/national-preparedness-goal

Guha-Sapir, D., Hoyois, P., \& Below, R. (2012). Annual disaster statistical review 2012; The numbers and trends. Retrieved from Center for Research on he Epidemiology of Disasters: http://reliefweb.int/sites/reliefweb.int/files/resources/ADSR_2012.pdf

Hoover, W. A. (1996). The practice implications of constructivism. SEDL Letter, 9(3). Retrieved from http://www.sedl.org/pubs/sedletter/v09n03/practice.html

Hutchinson, S. W., Haynes, S., Parker, P., Dennis, B., Mclin, C., \& Welldaregay, W. (2011). Implementing a multidisciplinary disaster simulation for undergraduate nursing students. Nursing Education Perspectives, 32(4), 240-243. http://dx.doi.org/10.5480/1536-502632.4 .240

Jakeway, C. C., Larosa, G., Cary, A., \& Schoenfisch, S. (2008). The role of public health nurses in emergency preparedness and response: A position paper of the association of state and territorial directors of nursing. Public Health Nursing, 25(4), 353-361. http://dx.doi.org/10.1111/j.1525-1446.2008.00716.x

Kaplan, B. G., Connor, A., Ferranti, E. P., Holmes, L., \& Spencer, L. (2011). Use of an emergency preparedness disaster simulation with undergraduate nursing students. Public Health Nursing , 29(1), 44-51. http://dx.doi.org/10.1111/j.1525-1446.2011.00960.x

Khan, A. S. (2011). Public health preparedness and response in the USA since 9/11: A national health security imperative []. The Lancet, 378, 953-956. Retrieved from http://www.cdc.gov/phpr/documents/Lancet_Article_Sept2011.pdf

Kuntz, S. W., Frable, P., Qureshi, K., \& Strong, L. L. (2008). Association of community health nursing educators: Disaster preparedness white paper for community/public health nursing educators. Public Health Nursing, 25(4), 362-369. http://dx.doi.org/10.111/j.1525-1446.2008.00717.x 
Lavin, R. (2006). HIPAA and disaster research: Preparing to conduct research. Disaster Management \& Response, 4(2), 32-37. Retrieved from www.nursingconsult.com/.../s1540248706000046.pdf?..

McEwen, M., \& Wills, E. M. (2011). Theoretical basis for nursing (3 ed.). New York: Lippincott Williams \& Wilkins.

Merchant, R. M., Leigh, J. E., \& Lurie, N. (2010). Health care volunteers and disaster response-first, be prepared. . New England Journal Of Medicine, 36(2), 872-873. http://dx.doi.org/10.1056/NEJMp1001737

National Association of County and City Health Officials. (2012). Local health department job losses and program cuts: findings from January 2012 survey [Survey findings]. Retrieved from http://www.naccho.org/advocacy/resources/upload/LHD-Budget-Cuts-twopager.pdf

National Hurricane Center. (2012). Hurricanes in history. Retrieved from NOAA: http://www.nhc.noaa.gov/outreach/history/\#katrina

National League for Nursing. (2006). Excellence in nursing education model. Retrieved from http://www.nln.org/excellence/model/

National Student Nurses' Association. (2013). Guidelines for planning; Disaster preparedness, recovery and relief []. Retrieved from www.nsna.org/Portals/0/.../NSNA/.../Disaster\%20Guidelines\%202013_14..._

National Weather Service. (2012). 2012 Atlantic hurricane season review. Retrieved from http://www.srh.noaa.gov/bro/?n=2012event_hurricaneseasonwrap

Olivia, F. W., Claudia, L. K., \& Yuen, L. A. (2009). Nurses' perception of disaster: Implications for disaster nursing curriculum. . Journal Of Clinical Nursing, 18(22), 3165-3171. http://dx.doi.org/10.1111/j.1365-2702.2008.02777.x 
Pang, S., Chan, S., \& Cheng, Y. (2009). Pilot training program for developing disaster nursing competencies among undergraduate students in China. Nursing and Health Sciences, 11(4), 367-373. http://dx.doi.org/10.1111/j.1442-2018.2009.00499.x

Peters, M. (2000). Does constructivist epistemology have a place in nurse education? Journal Of Nursing Education, 39(4), 166-170. http://dx.doi.org/Retrieved from

Peterson, C. A. (2006). Be safe, be prepared: Emergency system for advance registration of volunteer health professionals in disaster response. Online Journal of Issues in Nursing, 11(3).

Rogers, B., \& Lawhorn, E. (2007). Disaster preparedness: Occupational and environmental health professionals' response to Hurricanes Katrina and Rita. AAOHN Journal, 55(5), 197-207.

Schmidt, C. K., Davis, J. M., Sanders, J. L., Chapman, L. A., Cisco, M. C., \& Hady, A. R. (2011). Exploring nursing students' level of preparedness for disaster response. Nursing Education Perspectives, 32(6), 380-383. http://dx.doi.org/10.5480/1536-5026-32.6.380

Shiao, J., Koh, D., Lo, L., Lim, M., \& Guo, Y. (2007). Factors predicting nurses' consideration of leaving their job during the SARS outbreak. Nursing Ethics, 14(1), 5-17. http://dx.doi.org/10.1177/0969733007071350

Slepski, L. A. (2005). Emergency preparedness: Concept development for nursing practice. Nursing Clinicians of North America, 40(), 419-430. http://dx.doi.org/10.1016/j.cnur.2005.04.011

Steed, C. J., Howe, L. A., Pruitt, R. H., \& Sherrill, W. W. (2003). Integrating bioterrorism education into nursing school curricula. Journal of Nursing Education, 43(8), 362-367.

Turnock, B. J. (2012). Public Health: What is it and how it works (5th ed.). Boston: Jones and Bartlett. 
U.S. Department Of Health and Human Services. (2012). Preparedness. Retrieved from Healthy People 2020:

http://www.healthypeople.gov/2020/topicsobjectives2020/overview .aspx?topicId=34

U.S. Department of Health and Human Services. (2013). Pandemic and all hazards

preparedness act. Retrieved from Public Health Emergency:

http://www.phe.gov/preparedness/legal/pahpa/Pages/default.aspx

Veenema, T. G. (2006). Expanding educational opportunities in disaster response and emergency preparedness for nurses. Nursing Education Perspectives, 27(2), 93-99.

Weiner, E., Irwin, M., Trangenstein, P., \& Gordon, J. (2005). Integrating bioterrorism education into emergency preparedness curriculum in nursing schools in the United States. Nursing Education Perspectives, 26(6), 334-339.

Wisconsin Flu Resource. (n.d.). Ethics of health care disaster preparedness. Retrieved from http://pandemic.wisconsin.gov/docview .asp?docid=14447

World Health Organization. (2007). World disasters report focus on discrimination. Retrieved from The International Federation of Red Cross and Red Crescent Societies: http://www.ifrc.org/PageFiles/89755/2007/WDR2007-English.pdf

World Health Organization. (2007b). Risk reduction and emergency preparedness: WHO sixyear strategy for the health sector and community capacity development [strategy report]. Retrieved from World Health Organization:

http://www.who.int/hac/techguidance/preparedness/emergency_preparedness_eng.pdf

Yonge, O., Rosychuk, R. J., Bailey, T. M., Lake, R., \& Marrie, T. J. (2010). Willingness of university nursing students to volunteer during a pandemic. Public Health Nursing, 27(2), 174-180. http://dx.doi.org/10.1111/j.1525-1446.2010.00839.x

Appendix A

\section{Pre/Post Survey}

Please circle Yes or No for the following questions. If you answer, "yes" on question \#3 please list the organization(s). 
1. Do you currently have a personal preparedness disaster plan? YES or NO

2. Are you willing to respond as a student nurse or as a graduated nurse during a public health disaster? Yes or NO

3. Are you presently pre-registered with a volunteer disaster response organization such as but not limited to, the Medical Reserve Corps or the American Red Cross? Yes or No

If yes, please list organization(s)

\section{Appendix B}

Course Evaluation

Please complete the following evaluation regarding the course content and presenter.

1. Please rate how well the learning objectives were met

\begin{tabular}{|l|c|c|c|c|c|}
\hline \multicolumn{1}{|c|}{$\begin{array}{c}\text { Learning } \\
\text { Objectives }\end{array}$} & $\begin{array}{c}\text { Strongly } \\
\text { Disagree }\end{array}$ & Disagree & $\begin{array}{c}\text { Neither } \\
\text { Agree or } \\
\text { Disagree }\end{array}$ & Agree & $\begin{array}{c}\text { Strongly } \\
\text { Agree }\end{array}$ \\
\hline Define Disasters & 1 & 2 & 3 & 4 & 5 \\
\hline $\begin{array}{l}\text { Describe the importance of } \\
\text { personal preparedness and } \\
\text { explain how to create an } \\
\text { individualized plan }\end{array}$ & 1 & 2 & 3 & 4 & 5 \\
\hline
\end{tabular}




\begin{tabular}{|l|c|c|c|c|c|}
\hline & & & & & \\
\hline $\begin{array}{l}\text { List major public health threats } \\
\text { that could require a disaster } \\
\text { response effort }\end{array}$ & 1 & 2 & 3 & 4 & 5 \\
\hline $\begin{array}{l}\text { Identify professional roles and } \\
\text { responsibilities of a nurse } \\
\text { responding to a public health } \\
\text { emergency }\end{array}$ & 1 & 2 & 3 & 4 & 5 \\
\hline $\begin{array}{l}\text { Discover ethical and legal } \\
\text { considerations for a nurse } \\
\text { during a disaster. }\end{array}$ & 1 & 2 & 3 & 4 & 5 \\
\hline $\begin{array}{l}\text { List opportunities for } \\
\text { continuing education }\end{array}$ & 1 & 2 & 3 & 4 & 5 \\
\hline $\begin{array}{l}\text { Identify ways to volunteer } \\
\text { before, during and after a } \\
\text { disaster. }\end{array}$ & 1 & 2 & 3 & 4 & 5 \\
\hline
\end{tabular}

2. Please rate the presenter, Sandra Burnock and teaching methods utilized

\begin{tabular}{|l|c|c|c|c|c|}
\hline & $\begin{array}{l}\text { Strongly } \\
\text { Disagree }\end{array}$ & Disagree & $\begin{array}{l}\text { Neither } \\
\text { Agree or } \\
\text { Disagree }\end{array}$ & Agree & $\begin{array}{l}\text { Strongly } \\
\text { Agree }\end{array}$ \\
\hline $\begin{array}{l}\text { The presenter was knowledge } \\
\text { able about the topic }\end{array}$ & 1 & 2 & 3 & 4 & 5 \\
\hline $\begin{array}{l}\text { The presenter utilized } \\
\text { appropriate teaching } \\
\text { strategies to meet course } \\
\text { objectives }\end{array}$ & 1 & 2 & 3 & 4 & 5 \\
\hline
\end{tabular}

Comments or suggestions for course:

\section{Appendix C}

\section{E-mail Contact Information}

Please write your e-mail address below. This information will be collected by the student investigator, Sandra N. Burnock, and maintained confidential. You will receive two e-mails to the address provided asking you to complete a 5-minute post survey. If you do not wish to receive the e-mail reminders about the post survey please contact me at sandra.burnock@gmail.com or 508-212-0454. You may also contact my faculty advisor, Kathleen Gremel at kgremel@ric.edu, or 401-456-9565.

\section{E-Mail:}




\section{Appendix D}

\section{Dear Student,}

My name is Sandra N. Burnock and I am a nursing graduate student at Rhode Island College. I am writing to ask you to participate in a research study about emergency preparedness and education of undergraduate nursing students. Please read this letter and ask any questions that you may have before deciding whether to be in the study.

The goal of the program is to introduce the topic of disaster preparedness to nursing students and gauge the impact this introduction has on personal preparedness and willingness to respond during a disaster. Evidence suggests that nurses who receive education in school are more likely to volunteer in a disaster post graduation. The purpose of this project is to determine if a disaster preparedness educational intervention for nursing students' results in engaging students in personal preparedness and in a willingness to respond during a public health emergency.

You have been selected as a possible participant because of your current enrollment in NURS 370 Public and Community Health Nursing course. It is important for you to know that all surveys and course evaluations will be kept anonymous. In addition, all e-mail addresses will be kept confidential. In any sort of report that might be published, the researcher will not include any information that will make it possible to identify you. Research records will be kept in a secured file, and access will be limited to the researcher. Your participation is completely 
voluntary. Participation is not required to fulfill the course requirements of NURS 370 Public and Community Health Nursing. You can choose not to participate in this research and it will have no effect on your grades. Also, you can change your mind about participating at any time with no negative consequences.

As a chosen participant, you will be asked to do the following things

- Complete a pre-survey regarding your current personal preparedness and emergency preparedness engagement

- Participate in a 50 minutes educational intervention consisting of both lecture and case study discussions; this will take place during your regularly scheduled NURS 370 class time.

- Provide the student investigator with an e-mail address where you will receive two emails asking you to complete a post survey

- The educational intervention with pre-survey will take approximately $60 \mathrm{~min}$. In addition, the post survey will take an additional 5 minutes outside of class time.

- You will not be compensated for your involvement.

The risks of participation are minimal, meaning that they are about the same as what you would experience in your normal daily activities. The course content may have minimally disturbing material and images regarding disasters and the effects of disasters. There are no direct benefits to you for participating in the study.

You may ask any questions you have now. If you have any questions later, you may contact me at sandra.burnock@gmail.com or 508-212-0454. You may also contact my faculty advisor, Kathleen Gremel at kgremel@ric.edu, or 401-456-9565. If you think you were treated unfairly or would like to talk to someone other than the researcher about your rights or safety as a research participant, please contact Dr. Christine Marco, Chair of the Rhode Island College Institutional Review Board at IRB@ @ic.edu, or by phone at 401-456-8598, or by writing to Dr. Christine Marco, Chair IRB; c/o Department of Psychology, Horace Mann Hall 311; Rhode Island College; 600 Mount Pleasant Avenue; Providence, RI 02908.

Please keep this letter for your records.

Completion of the survey's implied that you have read and understand the above information, and are agreeing to participate in the study.

Thank you for your time,

Sincerely,

Sandra N. Burnock, BSN, RN 
Appendix E

\section{E-mail \#1}

Dear Students,

Two weeks ago you agreed to participate in a research study evaluating if a disaster preparedness educational intervention for nursing students' results in engaging students in personal preparedness and in a willingness to respond during a public health emergency.

Below, please find the link to complete the post survey. Please remember that participation is completely voluntarily and anonymous. Completion of the survey will not affect your grade in NUR 370.

In one week you will receive a final e-mail reminder to complete the post survey. If you wish not to receive this e-mail or have questions or concerns related to this research please contact me at sandra.burnock@gmail.com or 508-212-0454. You may also contact my faculty advisor, Kathleen Gremel at kgremel@ric.edu, or 401-456-9565

Thank you for your time,

Sincerely,

Sandra N. Burnock, BSN, RN

Survey link 


\section{Appendix F}

E-mail \#2

Dear Students,

Three weeks ago you agreed to participate in a research study evaluating if a disaster preparedness educational intervention for nursing students' results in engaging students in personal preparedness and in a willingness to respond during a public health emergency.

This is the second e-mail reminder to complete the post survey.

Below, please find the link to complete the post survey. Please remember that participation is completely voluntarily and anonymous. Completion of the survey will not affect your grade in NUR 370.

This will be the last correspondence you will receive from me. If you have any questions or concerns regarding this study please contact me at sandra.burnock@gmail.com or 508-212-0454. You may also contact my faculty advisor, Kathleen Gremel at kgremel@ric.edu, or 401-4569565

Thank you for your time,

Sincerely,

Sandra N. Burnock, BSN, RN

Survey link 